\title{
Passagem de testemunho
}

Cumpre-me colocar o leitor de sobreaviso: isto não é propriamente um editorial. Então o que é? Talvez uma maneira de descer ao baú das ideias e memórias, umas indeléveis, outras já coçadas e gastas pelas vicissitudes do tempo. Para quê? Para tentar transmitir a outros um valioso testemunho; estou convencido de que o seu abandono constituiria uma perda irreparável.

1. Para trás ficaram muitos anos, deveras preenchidos. Por isso, não me lembro bem de pormenores significantes; mas creio que foi nos finais de janeiro de 1988 ou de 1989. Era noite; o telefone tocou em minha casa. Atendi e percebi logo que a chamada vinha do estrangeiro. Vinha de Londres, e o interlocutor era o Professor Doutor Alfredo Gomes de Faria Júnior, Docente no Instituto de Educação Física e Desportos da Universidade do Estado do Rio de Janeiro (IEFDUERJ). Não o conhecia pessoalmente, mas tão somente como um nome pioneiro da Didática da Educação Física, através de obras de vulto, da sua autoria.

Ele manifestou vontade de vir ao Porto, para falarmos da criação de um movimento lusófono de cooperação na área das Ciências do Desporto e da Educação Física. Assim aconteceu. Passados 23 dias encontramo-nos, conforme o combinado, junto à estátua equestre de D. Pedro I do Brasil e IV de Portugal, erguida na Praça da Liberdade, ao fundo da Avenida dos Aliados. Seguiram-se a conversação e o delineamento do projeto, imediatamente agarrado com entusiasmo de teor religioso. Eis, num relato simples, o começo de algo destinado a ter uma história fulgurante.

2. O primeiro congresso realizou-se, em agosto de 1989, na cidade do Rio de Janeiro, mais concretamente nas instalações do IEFD-UERJ. O tema abrangente do mesmo foi dedicado à 'Aula de Educação Física'. E logo, naquele início naturalmente embrionário, ficou acordada e consagrada uma prática que tem vigorado até ao presente: a edição de trabalhos, tanto sob a forma de Atas ou Anais, como sob a forma de livro especialmente elaborado para congregar figuras da nossa área em torno do movimento.

O segundo congresso aconteceu no Porto, em janeiro de 1991. A instituição, hoje designada Faculdade de Desporto, chamava-se na altura ISEF-UP (Instituto Superior de Educação Física da Universidade do Porto). A inexistência de condições adequadas à grandeza do evento foi suprida pela utilização das excelentes instalações da Faculdade de Economia da UP. O evento decorreu de maneira magnífica, contando com uma larga representação de instituições e colegas do Brasil, Angola, Cabo Verde, Moçambique e Portugal, incluindo a participação de entidades governamentais.

Pode dizer-se que, a partir daquele momento, o movimento adquiriu um dinamismo que extravasou o seu âmbito e a humildade dos fins no início vislumbrados. Com efeito, ele constituiu a base para o estabelecimento de uma profícua cooperação entre instituições e pessoas, que até então se desconheciam e ou ignoravam completamente.

O terceiro congresso teve lugar na cidade de Recife, no início de setembro de 1992, organizado conjuntamente pelo Departamento de Educação Física da Universidade Federal de Pernambuco e pela Escola Superior de Educação Física da Universidade do Estado de Pernambuco. Além da edição de 2 grossos volumes, contendo os textos das intervenções, foi também publicado um catálogo referente a obras de arte expostas no congresso.

Não esperem de mim um historial rigoroso sobre os congressos seguintes, nem quanto aos

\footnotetext{
${ }^{1}$ Professor Catedrático Jubilado da Faculdade de Desporto da Universidade do Porto Autor correspondente: Praça de Malaca, nº 142, 4465-198 São Mamede de Infesta. E-mail: jbento.fadeup@gmail.com
} 
assuntos neles versados, nem quanto às datas da sua realização (neste caso, as datas dos congressos decorridos entre 1992 e 2002). Direi apenas que o barco do congresso percorreu um diversificado itinerário, tendo lançado a âncora nestes portos:

- Em 1993, Coimbra (FCDEF-UC);

- Em 1995, Maputo (Faculdade de Educação Física e Desporto da Universidade Pedagógica);

- Em 1997, A Corunha (INEF da Galiza);

- Em 1999, Florianópolis (UFSCUDESC);

- Em 2000, Lisboa (FMH-UTL);

- Em 2002, São Luís do Maranhão (Universidade Federal do Maranhão);

- $\quad$ Em 2004, Porto (FCDEF-UP);

- Em 2006, São Paulo (EEFE-USP);

- Em 2008, Porto Alegre (ESEF-UFRGS);

- Em 2010, Maputo (Faculdade de Educação Física e Desporto da Universidade Pedagógica);

- Em 2012, Belo Horizonte (Conselho Regional de Educação Física de Minas Gerais);

- Em 2014, Recife (Departamento de Educação Física da UFPE);

- Em 2016, Porto (FADE-UP);

- Em 2018, Fortaleza (UECEUniversidade Estadual do Ceará e Conselho Regional de Educação Física do Ceará).

3. Os trabalhos, constantes deste número especial da Revista Motricidade, constituem uma seleção feita entre os que foram apresentados no XVII CCDEFPLP, realizado em Fortaleza de 25 a 28 de setembro de 2018.

O congresso elegeu para tema geral um problema assaz importante e com implicação universal, inspirado numa desafiante $e$ responsabilizante encíclica do Papa Francisco: 'Cuidar da Casa Comum: da Natureza, da Vida, da Humanidade - Oportunidades e Responsabilidades do Desporto e da Educação Física'. Dedicada ao tema, foi elaborada e doada aos participantes no congresso uma obra de grande fôlego, dividida em dois cativantes volumes, perfazendo 700 páginas. Cabe aqui um sentido agradecimento à Casa da
Educação Física, Belo Horizonte, pela edição e distribuição gratuitas da obra.

Seja-me permitido tecer alguns considerandos acerca do extraordinário sucesso e dos resultados do congresso, porquanto ele constituiu um altíssimo marco geodésico na história e trajetória do movimento da lusofonia na área das Ciências do Desporto e de Educação Física.

Em primeiro lugar, porque a sua realização sobrepujou resistências que, de forma velada e até despudorada, apostaram tudo para a impedir, uma intenção já manifesta noutras ocasiões pelos acérrimos defensores da ditadura do inglês ('globish') e depreciadores do nosso idioma e do que nele se publica. Ora, como é sabido e se encontra amplamente comprovado, aquilo que não nos mata torna-nos mais fortes.

Em segundo lugar, porque a organização foi levada a cabo, de modo excecionalmente empenhado e proficiente, por instituições e pessoas com débil ligação ao movimento e, portanto, sem suficiente conhecimento da rede de contactos. O labor desenvolvido é, a todos os títulos, merecedor de justos encómios e louvores.

Em terceiro lugar, porque o sistema CONFEF/CREFs se associou, desde a primeira hora e num gesto de inequívoca e preciosa solidariedade, à efetivação do congresso e à defesa do seu espírito e legado, acrescentando-lhe uma avalização socioprofissional de inestimável e indelével valia.

Em quarto lugar, porque a adesão ao evento superou as melhores expectativas, não obstante as tentativas de boicote e desacreditação do mesmo, ativa e profusamente movidas nas mais distintas frentes. Atingiu-se um número recorde de inscrições e de instituições presentes no congresso.

Em quinto lugar, porque foi marcante a contribuição de colegas jovens, provenientes de uma larga panóplia de instituições, o que é um indicador da crescente atração irradiada pela lusofonia. Os curadores do movimento, reunidos no dia 26 de setembro, atribuíram a este facto o devido significado. Consequentemente, decidiram chamar à direção do movimento vários membros da jovem geração, visando levar por diante, com energias multiplicadas, a causa que 
congrega tanta gente nos países de língua oficial portuguesa. O testemunho foi entregue a novos protagonistas; doravante compete a eles empunhar e levar a tocha acesa até a uma meta, que se deseja sempre renovada.

Enfim, Fortaleza passou a ser um porto de ancoradoiro seguro do veleiro lusófono das Ciências do Desporto e da Educação Física. Um porto de chegada e igualmente de partida para aliciantes destinos. O próximo será, mais uma vez, a cidade de Maputo e a respetiva Faculdade de Educação Física e Desporto, que sediarão o XVIII congresso, a realizar de 5 a 8 de outubro de 2020. Seguir-se-ão a cidade e a simbólica Universidade de Coimbra, que acolherão o XIX, em 2022, na Faculdade de Ciências do Desporto e de Educação Física.

4. O que dizer sobre a qualidade dos trabalhos que perfazem este número especial da Revista Motricidade? Tendo passado pelo crivo de uma avaliação rigorosa, certamente eles congregam os méritos imprescindíveis à sua publicação. Não vou, pois, imiscuir-me nesse terreno, nem fazer o seu inventário, nem tampouco ousar esboçar uma análise da variedade de abordagens que eles expressam.

Aproveito a oportunidade, oferecida em bandeja de prata e que muito agradeço, para me entregar à formulação de algumas conexões, e proceder ao balanço que importa fazer. Para tanto quero concentrar-me no essencial e deixar de parte o acessório.

Poderá soar chocante; todavia, não renuncio à afirmação: nenhum congresso tem como objetivo cimeiro o nível científico das conferências e das comunicações nele proferidas. Quererá isto dizer que esse aspeto é despiciendo e não conta para nada? De maneira alguma! Não é isso que está em causa e pretendo salientar e trazer à colação. Quer, sim, significar que o objetivo último de um evento é constituir um palco atraente e credível de encontro de pessoas, de debate de ideias, de troca de pontos de vista, de construção de relações, de lançamento de pontes de comunicação e cooperação. O nível científico funciona como meio ao serviço de um fim que o inclui e transcende. Quanto mais alto ele for, tanto maior e melhor é a possibilidade de atingir os alvos que um movimento se propõe. Ou seja, o nível científico jamais pode ser descurado; carece de ser devidamente sopesado para favorecer e exaltar a consecução das finalidades pretendidas.

Isto aplica-se inteiramente ao congresso de Fortaleza e ao movimento de que ele faz parte. $\mathrm{O}$ património amealhado desde o primeiro congresso, realizado na UERJ em 1989, até ao momento pode ser evidenciado e resumido numa ementa de perguntas:

- Ao longo dos anos e simpósios transatos, quantas personalidades, instituições e entidades saíram do anonimato, do desconhecimento e da penumbra para o centro das atenções e considerações?

- Quantas parcerias institucionais foram estabelecidas, firmadas e consolidadas?

- Quantas pessoas passaram a conhecer-se e a cultivar amizades e cumplicidades?

- Quantos projetos de cooperação foram elaborados e concretizados?

- Quantos livros, ensaios e artigos foram escritos, em conjunto, por autores das diferentes paragens da lusofonia?

- Quantas conferências, reuniões e encontros conheceram a luz do dia, tendo como interventores especialistas oriundos dos países lusófonos?

- Quanta literatura e quantos nomes passaram a ser referenciados nos cursos de graduação e pós-graduação das instituições de formação e pesquisa dos nossos países?

- Que volume e relevância atingiu a mobilidade de docentes e de estudantes?

- Quantas centenas de jovens (e de adultos) deram asas à coragem, cometeram o arrojo de superar as origens e cruzaram os oceanos para realizar estudos de mestrado e de doutoramento, que jamais teriam realizado, se não existissem este movimento e as portas por ele abertas? Quantos iniciaram, com sucesso, os caminhos da ciência, da teoria e da docência universitária e se realizaram no plano académico e pessoal? 
- Quantos desconhecimentos acabaram, quantos preconceitos foram derrotados, quantas barreiras foram derrubadas, quantas costas voltadas foram substituídas por olhares de apreço, de curiosidade e confiança, quantas fraternidades foram edificadas, quantos abraços calorosos e afetuosos têm sido dados?

- Em síntese, quanta gente plantou, semeou e colheu benefícios, ideais, ilusões e sonhos de felicidade nas três décadas de existência do nosso congresso?!

Creio que as perguntas contêm em si as respostas; e estas são da ordem da admiração e do deslumbramento. Porventura, os colegas mais jovens não conseguem imaginar as diferenças entre o que a realidade foi no passado e o que é no presente; conhecem o 'depois', mas ignoram o 'antes' da existência do congresso. Hoje olham, com toda a naturalidade, um panorama que os empolga e arrebata para os céus da ideação.

Esse olhar tem implícito um compromisso: compete-lhes transportar o testemunho que receberam de quantos dedicaram a sua vida e paixão a uma causa que a todos congrega. Por favor, não o deixem cair; ao invés, levem-no renovado e aumentado de assombro e luz, inteiro e limpo para metas cada vez mais belas, exigentes e sublimes!

É precisamente isto que esperamos dos autores destes textos e de tantos outros que sonham com um futuro radioso. Fiquem cientes de que confiamos em vós e investimos a nossa esperança na vossa capacidade de assumir responsabilidades e de estar à altura das circunstâncias. Aceitem o nosso comovido e profundo reconhecimento. Bem hajam, em todo o tempo e lugar!

All content of Journal Motricidade is licensed under Creative Commons, except when otherwise specified and in content retrieved from other bibliographic sources. 